\title{
Research on Pricing and Coordination Strategy of a Sustainable Green Supply Chain with a Capital-Constrained Retailer
}

\author{
Liming Zhao, ${ }^{1}$ Ling Li $\left(\mathbb{D},{ }^{1}\right.$ Yao Song, ${ }^{2}$ Cong Li, ${ }^{1}$ and Yujie Wu $\mathbb{D D}^{1}$ \\ ${ }^{1}$ College of Management and Economics, Tianjin University, 92 Weijin Street, Tianjin 300072, China \\ ${ }^{2}$ Greatwall Strategy Consultants, 5 Meiyuan Street, Tianjin 300384, China \\ Correspondence should be addressed to Ling Li; liling1989@tju.edu.cn
}

Received 12 July 2017; Accepted 14 December 2017; Published 23 January 2018

Academic Editor: Hua Fan

Copyright (c) 2018 Liming Zhao et al. This is an open access article distributed under the Creative Commons Attribution License, which permits unrestricted use, distribution, and reproduction in any medium, provided the original work is properly cited.

\begin{abstract}
With the gradual deepening of environmental problems and the increase in consumer awareness of environmental protection, many enterprises have already begun to pay attention to green supply chain management. However, the price of green products is higher than that of nongreen products, which is an enormous challenge for many small- or medium-sized enterprises. To study the pricing and coordination of green supply chains under capital constraints, a model consisting of a manufacturer and a capital-constrained retailer is established; the manufacturer invests in green products and provides a deferred payment contract. Setting the situation without capital constraints as a benchmark, this study explores the impact of the retailer's capital constraints on the manufacturer's product greenness design; an interesting result shows that deferred payment can help encourage the retailer to order more products and improve the profit of the manufacturer and the efficiency of the entire supply chain as well as the product's greenness level simultaneously. However, the profit of the retailer will be hurt by the deferred payment contract. Therefore, to guarantee the profit of the entire channel and to make the two agents obtain a win-win outcome, a new two-way revenue-sharing contract is designed to coordinate the green supply chain.
\end{abstract}

\section{Introduction}

With the rapid development of the modern economy, the contradictions among economic development, resource utilization, and environmental protection are becoming increasingly prominent. Environmental pollution, waste of resources, and ecological imbalance have become hot issues of worldwide attention [1-3]. With economic development and consumer awareness of environmental protection improving, the idea of using traditional supply chains for manufacturing has not been able to meet the needs of sustainable social development. Therefore, green supply chain management (GSCM), which considers environmental protection and resource saving, emerges as the times require [4].

The green supply chain concept was first proposed by the Institute for Manufacturing Research at Michigan State University in 1996. This concept takes the environmental impacts and resource optimization in the supply chain into account, aiming to reduce the negative impact of the supply chain on the environment and to improve resource utilization [5].

After the green supply chain was proposed, it stimulated extensive research in academia. Srivastava [6] defined the green supply chain concept as "integrating environmental thinking into supply chain management, including product design, material sourcing and selection, manufacturing processes, delivery of the final products to the consumers, and end-of-life management of the product after its useful life." Green Jr. et al. [7] found that the green supply chain could effectively improve environmental and economic benefits and could promote enterprises to continue to invest in green products.

Consumer preference for environmentally friendly products is one of the important drivers for improving the quality of green products and increasing the profits of supply chain members. Pujari [8] thought that with the increase in consumer environmental awareness, consumers would be 
willing to pay a higher price for green products. Mu and Li [9] thought that consumer attention to environmental protection could effectively improve the profitability and competitiveness of green product manufacturers. Dumrongsiri et al. [10] proposed that the environmental preference of consumers would directly affect the price of green products and the overall performance of the green supply chain. Martinsen and Björklund [11] found that consumer demand for environmentally friendly products is increasing. Lin and Huang [12] found that there are two main reasons why consumers buy green products: to meet their own needs for environmental safety and because the purchase of green products reflects the social responsibility of consumers.

With the wide attention of society on green products and the improvement of consumer environmental awareness [13] to promote sustainable development and gain more competitive advantages in the long run [14], manufacturers have implemented green supply chain strategies. Retailers, which are other important members of the green supply chain, are faced with many difficulties and tests in the process of implementing a green supply chain. The implementation of a green supply chain can improve the enterprise's resource utilization and brand image in the long run, but, in the short term, green products are typically priced at a higher level [15]. Moreover, in China, retailers are typically smallor medium-sized enterprises whose financial strength is not very strong, which means that retailers do not have the strength to implement GSCM. Due to limited available capital or other strategic reasons, a quick payment may be difficult for retailers (especially start-ups and small- and mediumsized enterprises) in their transactions. Trade credit has developed as a common method for addressing this problem in supply chain management. This method is similar to the delayed payment contract. Under this contract, if the retailer does not have sufficient capital, then the manufacturer can provide products or services to the retailer first without getting paid. After a period of time, the retailer will repay the loan and interest to the manufacturer [16, 17]. For example, trade credit has been the main capital source for Wal-Mart, which may be higher than bank credit [18]. In the Boeing 787 Dreamliner programme, a risk-sharing contract is signed with the company's strategic suppliers. Under this contract, Boeing does not need to make payment before airplanes are delivered to customers [19].

Thus, to satisfy consumer' improving environmental awareness and optimize the economic benefits, manufacturers seem to have incentives to improve the degree of greenness of their products. However, a high degree of greenness always means a high price. Thus an interesting question occurs: If the retailer does not have sufficient capital to purchase the products, how should manufacturers design the products' greenness level? To address this question, this study establishes a model consisting of a manufacturer and a capital-constrained retailer in a green supply chain, and three scenarios are considered: an integrated situation, a decentralized situation without capital constraints, and additionally a decentralized situation with capital constraints and a deferred payment contract is provided. The main contributions of this paper are as follows. First, to the best of our knowledge, this is the first paper to introduce the capital constraint problem into GSCM using Stackelberg game. Second, an interesting result shows that manufacturers prefer to provide a deferred payment contract to a capitalconstrained retailer under certain conditions. Finally, a new two-way revenue-sharing contract is designed to coordinate the green supply chain, and a win-win outcome is obtained.

The remainder of this paper is structured as follows. The relevant GSCM literature and model development are discussed in Section 2. Section 3 derives the equilibrium solutions in the centralized situation, in the decentralized situation without capital constraints, and in the decentralized situation with capital constraints. A new two-way revenuesharing contract is designed to coordinate the green supply chain in Section 4 and to conduct a numerical experiment in Section 5. Section 6 concludes this paper, and all proofs are collected in the appendix.

\section{Literature Review and Model Development}

2.1. Literature Review. The research on pricing and coordination strategy of a sustainable green supply chain with a capital-constrained retailer has a very important significance for green supply chain management. Many scholars have launched a related research about green supply chain. In this section, the literature related to our work can be divided into three streams. The first stream is the manufacturer's green production, the second stream explores the retailer's capital constraints, and the third stream includes green supply chain coordination. Here the recent literature is as follows.

2.1.1. The Manufacturer's Green Production. The green production can enhance the market competitiveness of products, improve the favorability of consumer, and then expand the market share and promote the sustainable development of manufacturers. As a result, many manufacturers have begun to invest in green products.

Amacher et al. [20] studied how to formulate a green technology investment strategy according to the different cost structures to gain competitive advantages. Liu and Cruz [21] studied the price strategy of green products and the influence of green products on market demand from the manufacturer's perspective. Xia and $\mathrm{He}$ [22] noted that sharing the carbon emission reduction costs was an effective measure to promote the implementation of green supply chains. Abdullah et al. [23] found that the obstacles encountered in the implementation of green products, green processes, and green systems were different based on an empirical study on green innovation activities concerning more than 100 manufacturing enterprises in Malaysia. Zhang et al. [24] compared and analysed the price strategy and green innovation strategy of the manufacturer under the green supply chain framework. Basiri and Heydari [25] established a green supply chain model that included a manufacturer and a retailer to study the coordination of green supply chains. In this model, the green quality of the product was determined by the manufacturer. Yu et al. [26] studied the manufacturer's optimal production decisions under different green input levels under the premise of fully considering consumer environmental 
awareness and government support. Xu et al. [27] studied how to reduce carbon emissions per unit of product by adding the green technology input under cap-and-trade regulation to promote sustainable environmental development. Scur and Barbosa [28] studied and analysed the home appliance industry's green supply chain management practice through 5 manufacturers and 2 professional associations in Brazil and further put forward the relevant recommendations on how to implement green supply chain management in the home appliance industry.

2.1.2. The Retailer's Capital Constraints. Collecting the existing literature on green supply chains, there are no relevant studies concerning capital-constrained retailers in GSCM. The existing literature on capital-constrained retailers is focused on traditional supply chain research. The related literature is as follows.

Lai et al. [29] examined how financial constraints affect supply chain efficiency under the preorder mode and the consignment mode. Lee and Rhee [30] considered a newsvendor problem under trade credit and bank credit. These researchers showed that a trade-credit contract is dominant over bank credit in a centralized situation. Lee and Rhee [31] further analysed this problem in a supply chain; a contract combining trade credit and markdown allowance could coordinate the supply chain. Luo and Zhang [32] derived the equilibrium solution under trade credit with asymmetric information. Jing et al. [33] explored a supply chain with one manufacturer and one capital-constrained retailer and with both bank credit and trade credit available. The results showed that if the production cost is relatively small, then the retailer will prefer trade-credit financing; otherwise, bank credit financing is preferred. Taleizadeh et al. [34] showed that in reality, manufacturers often have strong financial capabilities and that to facilitate transactions they typically provide commercial credit to capital-constrained retailers. Cai et al. [35] studied how capital-constrained retailers make a choice between bank credit and transaction credit and verified the results through empirical research. Chen[19] investigated a supply chain with a manufacturer and a capitalconstrained retailer, and two ways of borrowing, from the bank or from the manufacturer, were discussed. Finally, a revenue-sharing contract was introduced to coordinate the supply chain. Hou et al. [36] built a single-stage supply chain model containing a manufacturer and a retailer and used bank funds to solve the problem of the retailer's funding constraints; manufacturers and retailers achieved supply chain coordination by sharing the financing cost and transfer payment. Shi et al. [37] studied the optimal order quantity and the optimal pricing problem of seasonal products under the conditions of market demand uncertainty and a capitalconstrained retailer. Shi et al. [38] designed a simple intelligent purchasing decision support system for the capitalconstrained retailers to help them determine the integrated procurement time, quantity, and financing decisions for the seasonal products.

From the above literature review, it can be seen that the retailers often have financial constraint problems in management practice. In the green supply chain, the green products usually have a higher wholesale price, which to some extent further exacerbated the capital pressure of retailers, so the retailers' financing problems become more important.

2.1.3. Green Supply Chain Coordination. The green supply chain management is one of the important ways to improve the environmental performance, and the development of green supply chain depends on the realization of green supply chain coordination [39]. To promote the further development of green supply chains, increasing numbers of studies are inclined to design a reasonable coordination mechanism and an incentive mechanism to realize green supply chain coordination and to maintain the benefits of supply chain members [40]. Barari et al. [41] studied how to establish a coordination mechanism concerning the environmental benefits and commercial interests between suppliers and retailers to promote the implementation of green supply chains. Swami and Shah [42] studied the green supply chain coordination problem in the centralization channel and decentralization channel; in this model, manufacturer and a retailer jointly invest in green innovation. Zhang and Liu [43] designed three mechanisms, including a revenue-sharing mechanism, a Shapley value coordination mechanism, and an asymmetric Nash coordination mechanism, to encourage supply chain members to increase their green input to realize green supply chain coordination. Xu and Gao [44] studied the pricing and coordination of green supply chains in the home appliance industry on the basis of game theory and contract coordination theory. Zhang et al. [45] studied how to effectively determine the coordination strategy of the product price and green supply chain coordination when green products and nongreen products exist simultaneously under the conditions of a cooperative game and a noncooperative game. Xie [46] first introduced regulation into green supply chain coordination and further analysed the influence of regulation on green product prices and energy efficiency levels. Hamdan and Cheaitou [47] designed a cost-sharing contract to motivate the manufacturer to increase its green input, but, unfortunately, the designed cost-sharing contract was not applied to the centralized decision. Ghosh and Shah [48] studied the role of the buy-back contract in the supply chain coordination of a two-stage supply chain; in this model, it is assumed that market demand is a function of product prices and green levels. Zhang et al. [49] extended the GSCM in a dual-channel supply chain and designed a two-part tariff contract to achieve coordination. Li et al. [50] designed a three-stage decision-making method to solve the problem of multiperiod green supplier selection and order allocation for all unit quantities in the green supply chain and achieved green supply chain coordination.

It can be seen from the above literature review that designing an incentive mechanism to realize green supply chain coordination is always a heated issue. Thus, our study wants to explore which contract can achieve the green supply chain coordination when the retailer has financial constraint pressure.

2.2. Model Development. This paper establishes a green supply chain model consisting of a single manufacturer and a 
single retailer in which they manage a single product in the market. Assume that the manufacturer invests to improve the degree of greenness of the product. The market demand is $x$, which is statistic and follows a uniform distribution in $(0, U)$. Thus, the demand can be denoted as follows:

$$
D=x+\beta e,
$$

where $e$ denotes the greenness of the product and $\beta$ is the sensitivity coefficient. Further, the unit production cost corresponding to the greenness $e$ is assumed to be $v e^{2}$, which is widely used in the existing literature [51].

The manufacturer's wholesale price is $w$, and the retailer's order quantity is $q$. Without loss of generality, assume that the retail price is exogenous and normalized to be 1 [32]. $\pi_{i}$ represents the expected profit of $i$ 's in the green supply chain, and $i=m, r, c$ refers to the manufacturer, retailer, and the entire green supply chain, respectively. Thus, the profit functions of the manufacturer and the retailer can be obtained:

$$
\begin{aligned}
& E\left(\pi_{m}\right)=\left(w-v e^{2}\right) q \\
& E\left(\pi_{r}\right)=p \min \{D, q\}-w q .
\end{aligned}
$$

In the centralized situation, the profit function is

$$
\pi_{c}=p \min \{D, q\}-v e^{2} q .
$$

\section{The Equilibrium Solutions}

3.1. The Centralized Green Supply Chain without Financial Constraints. In this subsection, to construct a benchmark for the analysis in the following, first consider the centralized green supply chain without capital constraints in which there is a central planner making decisions for the entire green supply chain. That is, the aim of our model is to choose an optimal degree of greenness $e$ and order quantity $q$ to maximize the total channel profit $\pi_{c}$. According to formula (4), the optimal solution of $\left(e_{c}^{*}, q_{c}^{*}\right)$ is shown in Proposition 1.

Proposition 1. Assuming that demand uncertainty $x$ follows a uniform distribution in $(0, U)$, there is a unique equilibrium solution in the centralized situation as follows.

(1) The optimal degree of greenness $e_{c}^{*}$ satisfies the following equation:

$$
2 e^{3} U v^{2}-3 e^{2} v \beta-2 e U v+\beta=0 .
$$

(2) The optimal order quantity is

$$
q_{c}^{*}=U-e_{c}^{* 2} U v+e_{c}^{*} \beta .
$$

3.2. The Decentralized Green Supply Chain without Financial Constraints. If the retailer does not have capital constraints, then the decision process is as follows. As a Stackelberg game leader, the manufacturer first determines the wholesale price and the degree of greenness. Second, the retailer, as a follower, after observing the manufacturer's decision, decides the order quantity. According to formulas (2) and (3), Proposition 2 can be obtained.
Proposition 2. Assuming the demand uncertainty $x$ follows a uniform distribution in $(0, U)$, there is a unique equilibrium solution in the decentralized situation as follows.

(1) The manufacturer's optimal wholesale price $w_{d}^{*}$ and product greenness $e_{d}^{*}$ are as follows:

$$
\begin{aligned}
& w_{d}^{*}=\frac{4 U^{2} v+3 \beta^{2}}{8 U^{2} v}, \\
& e_{d}^{*}=\frac{\beta}{2 U v} .
\end{aligned}
$$

(2) The retailer's optimal order quantity is

$$
q_{d}^{*}=\frac{U}{2}+\frac{\beta^{2}}{8 U v} .
$$

Observation 1. Consider the impact of the key parameters $U, v, \beta$ on the equilibrium solution under the case without financial constraints:

(1) $\partial w_{d}^{*} / \partial U=-3 \beta^{2} / 4 U^{3} v<0, \partial e_{d}^{*} / \partial U=-\beta / 2 U^{2} v<$ $0, \partial q_{d}^{*} / \partial U=1 / 2-\beta^{2} / 8 U^{2} v>0$;

(2) $\partial w_{d}^{*} / \partial v=-3 \beta^{2} / 8 U^{2} v^{2}<0, \partial e_{d}^{*} / \partial v=-\beta / 2 U v^{2}<$ $0, \partial q_{d}^{*} / \partial v=-\beta^{2} / 8 U v^{2}<0$;

(3) $\partial w_{d}^{*} / \partial \beta=3 \beta / 4 U^{2} v>0, \partial e_{d}^{*} / \partial \beta=1 / 2 U v>$ $0, \partial q_{d}^{*} / \partial \beta=\beta / 4 U v>0$.

The results in Observation 1(1) show that both the wholesale price and the greenness effort are decreasing in $U$ whereas the retailer's order quantity is increasing in $U$. The reason is that, with $U$ increasing, which indicates that the mean market demand $(U / 2)$ is increasing, the retailer has an incentive to increase the order quantity to satisfy the market demand, and the manufacturer would like to provide a low wholesale price level. In addition, it is not necessary for the manufacturer to invest more greenness effort to expand the market. In Observation 1, (2) and (3) demonstrate that the impact of $v$ and $\beta$ on the equilibrium solution is the opposite. These results correspond to our intuition.

3.3. The Retailer with Capital Constraints. This subsection analyses the situation in which the retailer has capital constraints in purchasing products from the manufacturer. Therefore, if the manufacturer wants to resort to the retailer to distribute its products, then it must provide a trade credit to the retailer. Then, the profits of the manufacturer and the retailer can be rewritten as

$$
\begin{aligned}
& \pi_{m}^{t d}=\min \{p D, w q\}-v e^{2} q \\
& \pi_{r}^{t d}=\{p \min \{D, q\}-w q\}^{+} .
\end{aligned}
$$

To simplify the calculation, the retailer's initial capital is assumed to be zero without loss of generality.

Proposition 3. Assuming demand uncertainty $x$ follows a uniform distribution in $(0, U)$ and the retailer has capital constraints, there is a unique equilibrium solution in the decentralized situation as follows. 
(1) The manufacturer's optimal wholesale price $w_{d}^{t *}$ and product greenness $e_{d}^{t *}$ are as follows:

$$
\begin{aligned}
w_{d}^{t *} & =p=1, \\
e_{d}^{t *} & =\frac{\sqrt{16 U^{4} v^{2}+80 U^{2} v \beta^{2}+\beta^{4}}-4 U^{2} v-\beta^{2}}{12 U v \beta} .
\end{aligned}
$$

(2) The retailer's optimal order quantity is

$$
q_{d}^{t *}=\frac{U}{3}+\frac{\sqrt{16 U^{4} v^{2}+80 U^{2} v \beta^{2}+\beta^{4}}-\beta^{2}}{24 U v} .
$$

Observation 2. $\partial e_{d}^{t *} / \partial U<0, \partial q_{d}^{t *} / \partial U>0, \partial e_{d}^{t *} / \partial v<$ $0, \partial q_{d}^{t *} / \partial v<0, \partial e_{d}^{t *} / \partial \beta>0, \partial q_{d}^{t *} / \partial \beta>0$.

The results in Observation 2 are similar to those in Observation 1. Therefore, the explanation is omitted. Recall that Propositions 2 and 3 have given the equilibrium solutions in the two situations. There is the problem of whether the manufacturer has an incentive to provide a deferred payment contract for the retailer if the retailer has capital constraints. In other words, how will the deferred payment contract have an effect on the optimal decisions and profits of the green supply chain?

Proposition 4. If $U^{2} v \geq 3 \beta^{2} / 4$, then the equilibrium solutions under the two situations, without and with capital constraints, have the following orders:

$$
\begin{aligned}
& w_{d}^{t *} \geq w_{d}^{*}, \\
& e_{d}^{t *}-e_{d}^{*} \begin{cases}\leq 0, & \text { if } \frac{3}{4} \beta^{2} \leq U^{2} v \leq 2 \beta^{2} \\
>0, & \text { if } U^{2} v>2 \beta^{2},\end{cases} \\
& q_{d}^{t *}>q_{d}^{*} .
\end{aligned}
$$

Proposition 4 indicates that, faced with a capitalconstrained retailer, the manufacturer would like to increase the product's greenness to attract more consumers in the market only if the coefficient of the greenness cost is small or the sensitivity parameter is great enough. Correspondingly, its marginal profit (wholesale price) is also increasing. It is interesting to find that although the wholesale price is increasing, the capital-constrained retailer's order quantity is also increasing. This finding means that once the manufacturer promises to offer a deferred payment contract, the retailer would rather bear more risk to order more products to satisfy the uncertain demand.

Proposition 5. The profits of the green supply chain members under the two situations, without and with capital constraints, have the following orders:

$$
\begin{aligned}
& \pi_{c}^{d t *}>\pi_{c}^{d *}, \\
& \pi_{m}^{d t *}>\pi_{m}^{d *}, \\
& \pi_{r}^{d t *}<\pi_{r}^{d *} .
\end{aligned}
$$

Proposition 5 explains the reason why, in reality, a majority of manufacturers prefer to offer a deferred payment contract for their retailers. The results show that under a deferred payment contract, the profits of both the manufacturer and the entire green supply chain will increase, but it is unfortunate to observe that the profit of the retailer decreases to 0 . In fact, under the deferred payment contract, the manufacturer sets a wholesale price that is equal to the retail price, the marginal profit of the retailer is zero, and all of its profit is held by the manufacturer. Thus, it is possible that the retailer does not have an incentive to take part in the sales process. Therefore, except for the deferred payment contract, the manufacturer must design another contract to guarantee the retailer's profit.

\section{Coordinate the Green Supply Chain with Finance Constraints}

This section tries to design a contract to coordinate the green supply chain not only to guarantee the profit of the entire channel but also to make the two agents obtain a win-win outcome, especially the capital-constrained retailer's profit. Referring to $\mathrm{Xu}$ et al. [52], adopt a two-way revenue-sharing contract that can be described as follows: the manufacturer obtains a fraction of the revenue generated by the capitalconstrained retailer, and the retailer simultaneously obtains a fraction of the revenue generated by the manufacturer. Assume that $\lambda_{r}\left(0<\lambda_{r}<1\right)$ represents the retailer's share of the sales profit in the retail channel and that $\lambda_{m}\left(0<\lambda_{m}<\right.$ 1) represents the manufacturer's share of the gross profit in the wholesale channel. Therefore, with this two-way revenuesharing contract, the profit functions of the two agents can be rewritten as follows:

$$
\begin{aligned}
\pi_{m}^{s d t}= & \lambda_{m}\left(\min \{p D, w q\}-v e^{2} q\right) \\
& +\left(1-\lambda_{r}\right)\{p \min \{D, q\}-w q\}^{+} \\
\pi_{r}^{s d t}= & \lambda_{r}\{p \min \{D, q\}-w q\}^{+} \\
& +\left(1-\lambda_{m}\right)\left(\min \{p D, w q\}-v e^{2} q\right) .
\end{aligned}
$$

Proposition 6. Under a two-way revenue-sharing contract $\left(\lambda_{m}, \lambda_{r}\right)$, the green supply chain can be coordinated only if $\lambda_{m}=1-\lambda_{r}$. This means that the profit of the entire green supply chain is equal to that in the centralized situation. Further, the entire profit (centralized) can be allocated arbitrarily between the manufacturer and the retailer by $\lambda_{m}$.

Proposition 6 not only guarantees that the profit of the green supply chain under contract is equal to the centralized situation but also can make the two agents obtain a win-win outcome. In fact, because the profit can be divided arbitrarily between them by share, there must be a zone guaranteeing the profits if the manufacturer and the retailer obtain a Pareto improvement. 


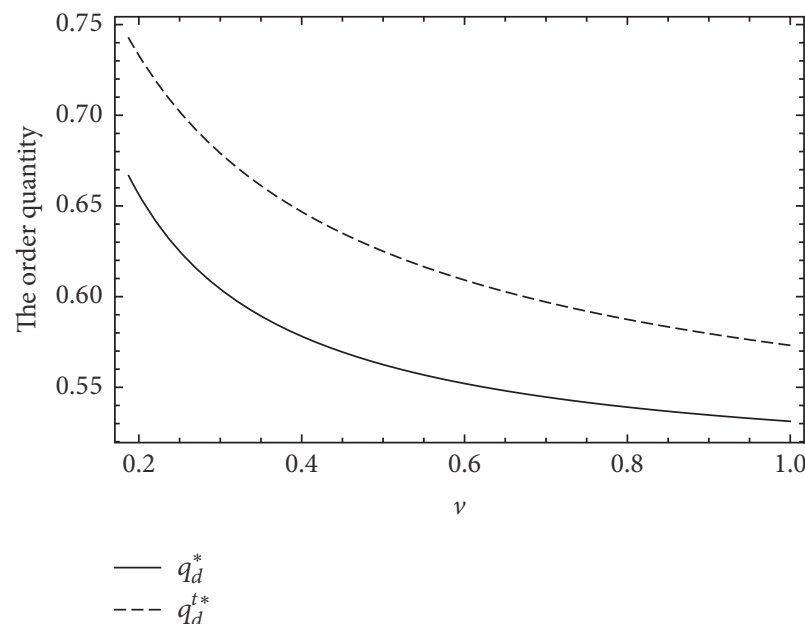

(a) The impact of $v$ on $q$

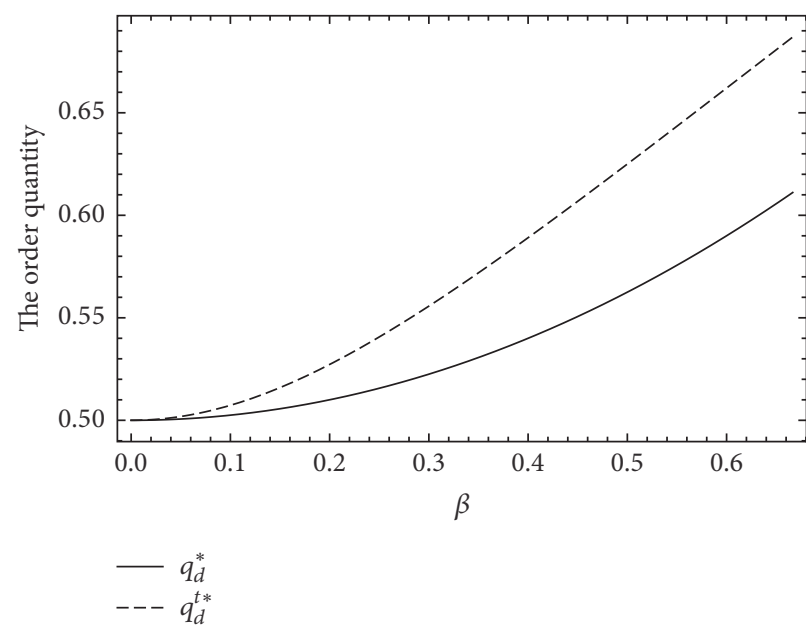

(b) The impact of $\beta$ on $q$

FIgURE 1: The impacts of $v, \beta$ on the optimal order quantity.

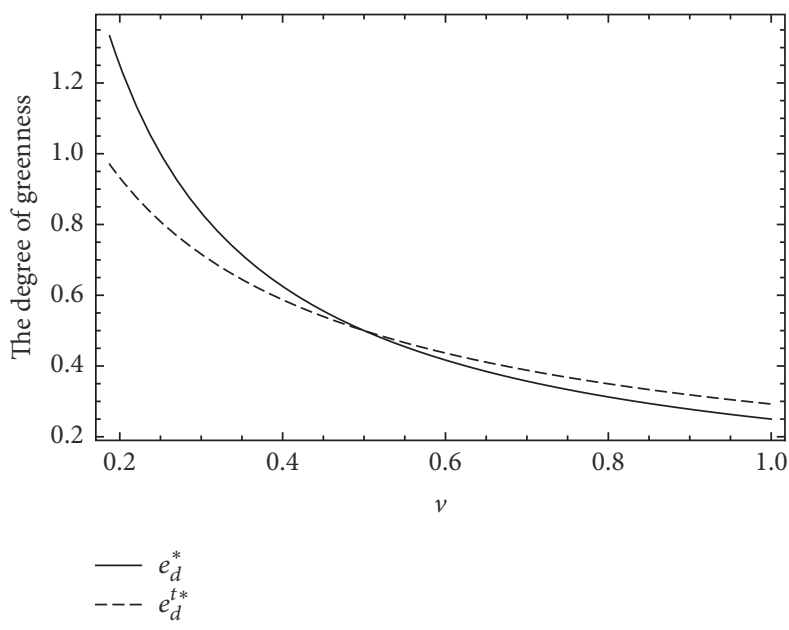

(a) $\beta=0.5$

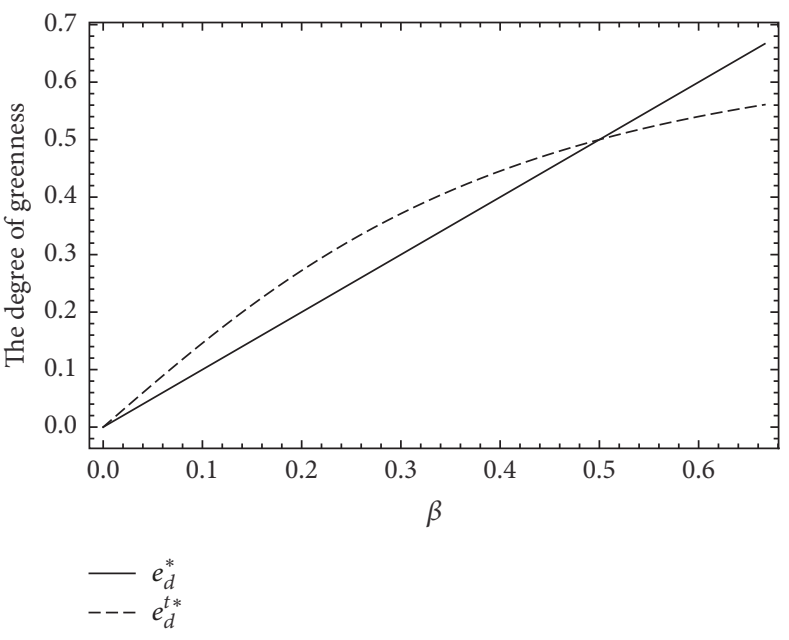

(b) $v=0.5$

Figure 2: The impacts of $v, \beta$ on the degree of greenness.

\section{Numerical Analysis}

In this section, to more clearly show the conclusions and illustrate the impact of the parameters to the optimal solutions, some numerical analyses are given.

5.1. Comparative Analysis. First, let us explore how the retailer's optimal order quantity is affected by the investing cost coefficient and the sensitive coefficient of greenness to the demand. Let $U=1$; then, we can obtain the figures.

Figure 1 shows that the trade-credit contract can encourage the capital-constrained retailer to increase the order quantity. However, with the coefficient of greenness cost increasing, Figure 2(a) shows that the manufacturer will decrease its investment; thus, demand will decrease, as well as the order quantity. In addition, with the sensitivity parameter $\beta$ increasing, the manufacturer will increase the greenness investment; thus, both the demand and the order quantity will increase.

On the other hand, Figure 2 implies that either $v$ is small or $\beta$ is large; the capital constraints can induce the manufacturer to set a relatively low greenness effort. Figure 2(a) shows that if the retailer has capital constraints and a deferred payment is provided, because both the wholesale price and the order quantity are increasing, then the manufacturer does not have an incentive to increase its greenness to expand its market share, which may damage its unit marginal profit. Similarly, the explanation of $\beta$ is similar to this. In short, the manufacturer has a trade-off between increasing the demand and increasing the unit marginal profit.

Define $\Delta \pi_{i}^{*}=\pi_{i}^{d *}-\pi_{i}^{d t *}$; then, Figure 3 is obtained.

It is easy to find that deferred payment can bring benefits for the manufacturer and the entire supply chain, though the profit of the retailer will be hurt. In addition, Figure 3 


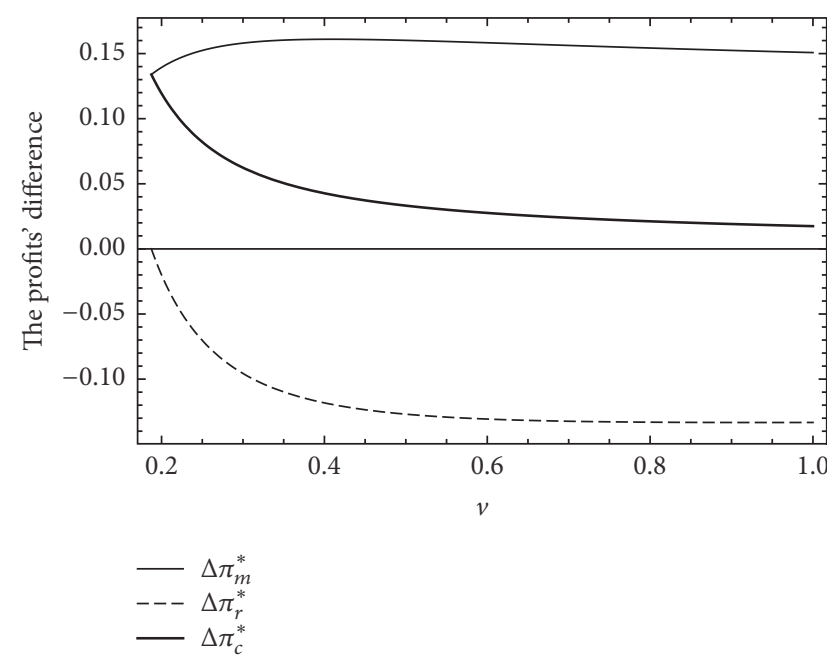

(a) The impact of $v$ on the profits

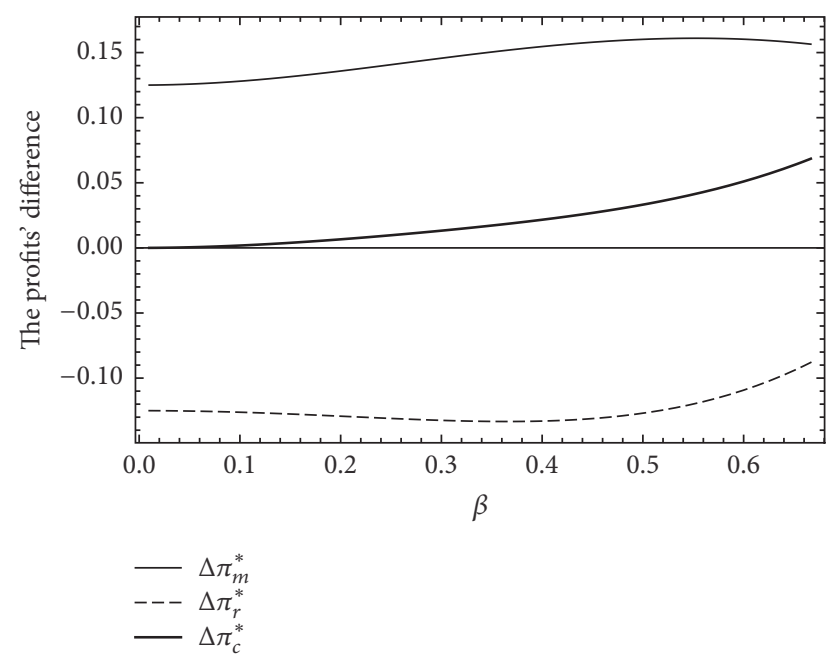

(b) The impact of $\beta$ on the profits

Figure 3: The impacts of $v, \beta$ on the members' profits.

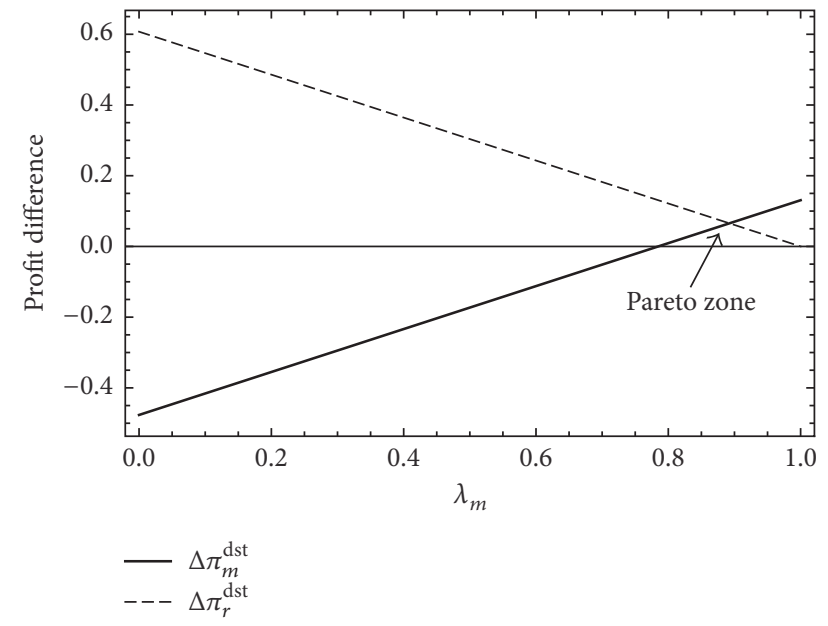

FIGURE 4: Channel coordination under the mixed contract.

demonstrates that a small level of $v$ or a great level of $\beta$ can alleviate this effect on the retailer.

5.2. Coordination. Under a two-way revenue-sharing contract, it has been verified that the supply chain can achieve coordination. Figure 4 illustrates our conclusion. Define $\Delta \pi_{i}^{d s t}=\pi_{i}^{d s *}-\pi_{i}^{d t *}$ as the difference between i's profit under the two-way revenue-sharing contract and without the contract. Then, there is a Pareto zone that not only guarantees that the profit in the decentralized situation is equal to that in the centralized situation but also makes the two agents obtain a win-win outcome.

\section{Conclusion}

With the deterioration of global warming and the ecological environment, green supply chain management as a new way to solve environmental problems has been a widespread concern for the whole society. One of the most important issues in green supply chain management is pricing and coordination strategy. This paper considers a green supply chain in which the manufacturer produces a green product and the retailer has capital constraints. Three scenarios of the model are analysed, the centralized situation, a decentralized situation in which the retailer has sufficient capital, and a decentralized situation in which the retailer has capital constraints.

All the equilibrium solutions are obtained and the sensitivity analysis results show that

(1) With the market demand increasing, the retailer will increase the order quantity while the manufacturer will decrease the product greenness. This result indicates that the manufacturer can obtain more profit from the sales amount, which means that it does not have an incentive to improve the product's greenness when facing a large market demand.

(2) Further, compared to the two decentralized situations, both the retailer's order quantity and the wholesale price are increased as the deferred payment contract is provided, whereas the manufacturer's greenness effort depends on the greenness cost coefficient and the sensitivity parameter. Specifically, only if the greenness cost coefficient is high enough or the sensitivity parameter is at a small level will the product's greenness increase. This finding helps explain why, in reality, manufacturers would like to provide deferred payment contract for retailers. Deferred payment can encourage the retailer to bear more risk to order more products to satisfy the uncertain demands, and the manufacturer may also improve the product's greenness.

(3) In addition, the results show that both the manufacturer and the entire green supply chain can benefit from the deferred payment contract, though the retailer's profit will be hurt. This analysis indicates that although the retailer's capital constraint increases the performance of the entire green supply chain, it hurts the retailer's profit; thus it is 
valuable to design a contract to coordinate the green supply chain. Thus, a two-way revenue-sharing contract is designed to achieve green supply chain coordination and verify that there is a Pareto zone making the two agents obtain a win-win outcome. In fact, combining the two-way revenue-sharing and deferred payment contracts, the performance of the entire supply chain with a capital-constrained retailer in a decentralized situation is equal to that without a capitalconstrained retailer in a centralized situation.

The applicability of contributions includes two aspects: on the one hand, the results provide solutions for the coordination mechanism problems encountered in the implementation, management, and operation of the green supply chain in reality; on the other hand, our conclusions provide new ideas in financing for small-scale and weak financial enterprises to participate in the green supply chain.

Building on previous studies, this paper makes a useful attempt in pricing and coordination strategy of a sustainable green supply chain with a capital-constrained retailer, which provides guidance for the development of green supply chain. However, there are still some limitations in this paper; firstly, this study only assumes the retailer has a capital constraint problem, while, in fact, the manufacturer may also not have sufficient capital to organize production; secondly, the market retail price in this paper is deterministic, but in practice it is usually uncertain.

Therefore, future study should consider the expansion from the following aspects: firstly, the manufacturer has a capital constraint or both the manufacturer and the retailer have capital constraints; secondly, considering a variety of financing methods, rather than being limited to internal financing within the green supply chain, is also an interesting direction; thirdly, assume that the market retail price is an endogenous variable.

\section{Appendix}

Proof of Proposition 1. In a centralized situation, the manufacturer determines $(e, q)$ to maximize the profit of the entire supply chain; the first-order condition is

$$
\begin{aligned}
& \frac{\partial \pi_{c}}{\partial e}=-2 e q v+\frac{\beta(q-e \beta)}{U}=0, \\
& \frac{\partial \pi_{c}}{\partial q}=1-e^{2} v-\frac{q-e \beta}{U}=0 .
\end{aligned}
$$

Thus $q_{c}^{*}=U-e^{2} U v+e \beta, e_{c}^{*}$ satisfies $2 e^{3} U v^{2}-3 e^{2} v \beta-$ $2 e U v+\beta=0$.

The Hessian matrix $\pi_{c}$ is as follows:

$$
H_{1}=\left[\begin{array}{cc}
-2 q v-\frac{\beta^{2}}{U} & -2 e v+\frac{\beta}{U} \\
-2 e v+\frac{\beta}{U} & -\frac{1}{U}
\end{array}\right] .
$$

It is obvious that $-2 q v-\beta^{2} / U<0$; then, on the equilibrium point $\left(e_{c}^{*}, q_{c}^{*}\right)$,

$$
\left|H_{1}\right|_{e=e_{c}^{*}, q=q_{c}^{*}}=\frac{2 v\left(U-3 e^{2} U v+3 e \beta\right)}{U},
$$

because

$$
\begin{aligned}
& 2 e^{3} U v^{2}-3 e^{2} v \beta-2 e U v+\beta=0 \Longrightarrow \\
& 2 e U v\left(1-e^{2} v\right)-\beta\left(1-3 e^{2} v\right)=0 \Longrightarrow \\
& 3 e^{2} v<1 \Longrightarrow \\
& U-3 e^{2} U v+3 e \beta>U-U+3 e \beta=3 e \beta>0 \Longrightarrow \\
& \left|H_{1}\right|_{e=e_{c}^{*}, q=q_{c}^{*}}=\frac{2 v\left(U-3 e^{2} U v+3 e \beta\right)}{U}>0 .
\end{aligned}
$$

Thus, Proposition 1 holds.

Proof of Proposition 2. From formula (3), due to $\partial^{2} \pi_{r}^{d} / \partial q^{2}=$ $-1 / U<0$, the retailer's optimal order quantity satisfies

$$
\frac{\partial \pi_{r}^{d}}{\partial q}=1-w-\frac{q-e \beta}{U}=0 .
$$

Thus $q_{d}=U-U w+e \beta$.

Substitute it into (2); then, according to the first-order conditions, there are

$$
\begin{aligned}
w_{d}^{*} & =\frac{4 U^{2} v+3 \beta^{2}}{8 U^{2} v}, \\
e_{d}^{*} & =\frac{\beta}{2 U v} .
\end{aligned}
$$

The Hessian matrix $\pi_{m}$ is as follows:

$$
H_{2}=\left[\begin{array}{cc}
-2 U & 2 e U v+\beta \\
2 e U v+\beta & -4 e v \beta-2 v(U-U w+e \beta)
\end{array}\right] .
$$

Because $-2 U<0$ and, on the equilibrium point, there is

$$
\left|H_{2}\right|_{e=e_{d}^{*}, w=w_{d}^{*}}=\frac{1}{2}\left(4 U^{2} v+\beta^{2}\right)>0 .
$$
holds.

Summarizing the above formulations, Proposition 2

Proof of Proposition 3. The deriving process is similar to Proposition 2; firstly, according to

$$
\begin{aligned}
\frac{\partial^{2} \pi_{r}^{t d}}{\partial q^{2}}= & -\frac{(p-w)(p+w)}{p U}<0, \\
\frac{\partial \pi_{r}^{t d}}{\partial q}= & -\frac{q(p-w)(p+w)}{2 p U} \\
& -\frac{(p-w)(q w+p(q-2(U+e \beta)))}{2 p U}=0,
\end{aligned}
$$


there is $q=p(U+e \beta) /(p+w)$. Then substitute it into (9):

$$
\begin{aligned}
& \frac{\partial \pi_{m}^{t d}}{\partial w} \\
& =\frac{p(U+e \beta)\left(e^{2} p U v+e^{2} U v w+p^{2}(U+e \beta)\right)}{U(p+w)^{3}}
\end{aligned}
$$$$
>0 \text {, }
$$

and then $w_{d}^{t *}=p$.

Now $\partial^{2} \pi_{m}^{t d} / \partial w^{2}=-U v-3 \operatorname{ev} \beta-\beta^{2} / 4 U<0$, and let $\partial \pi_{m}^{t d} / \partial e=0$; there is

$$
e=\frac{-4 U^{2} v-p \beta^{2}+\sqrt{16 U^{4} v^{2}+80 p U^{2} v \beta^{2}+p^{2} \beta^{4}}}{12 U v \beta} .
$$

Proof of Observation 2. One has

$$
\begin{aligned}
& \frac{\partial e_{d}^{t *}}{\partial U} \\
& =-\frac{\left(4 U^{2} v-\beta^{2}\right)\left(\sqrt{16 U^{4} v^{2}+80 U^{2} v \beta^{2}+\beta^{4}}-4 U^{2} v-\beta^{2}\right)}{12 U^{2} v \beta \sqrt{16 U^{4} v^{2}+80 U^{2} v \beta^{2}+\beta^{4}}} \\
& <0, \\
& \frac{\partial q_{d}^{t *}}{\partial U} \\
& =\frac{8 U^{2} v+\beta^{2}+\left(16 U^{4} v^{2}-\beta^{4}\right) / \sqrt{16 U^{4} v^{2}+80 U^{2} v \beta^{2}+\beta^{4}}}{24 U^{2} v} \\
& >0, \\
& \frac{\partial e_{d}^{t *}}{\partial v}=\frac{\beta\left(\sqrt{16 U^{4} v^{2}+80 U^{2} v \beta^{2}+\beta^{4}}-40 U^{2} v-\beta^{2}\right)}{12 U v^{2} \sqrt{16 U^{4} v^{2}+80 U^{2} v \beta^{2}+\beta^{4}}}<0, \\
& >0, \\
& \frac{\partial q_{d}^{t *}}{\partial \beta}=\frac{2\left(40 U^{2} v \beta+\beta^{3}\right) / \sqrt{16 U^{4} v^{2}+80 U^{2} v \beta^{2}+\beta^{4}}-2 \beta}{24 U v} \\
& \frac{\partial q_{d}^{t *}}{\partial v}=\frac{\beta^{2}\left(\sqrt{16 U^{4} v^{2}+80 U^{2} v \beta^{2}+\beta^{4}}-40 U^{2} v-\beta^{2}\right)}{24 U v^{2} \sqrt{16 U^{4} v^{2}+80 U^{2} v \beta^{2}+\beta^{4}}}<0, \\
& \frac{\partial e_{d}^{t *}}{\partial \beta} \\
& =\frac{\left(4 U^{2} v-\beta^{2}\right)\left(\sqrt{16 U^{4} v^{2}+80 U^{2} v \beta^{2}+\beta^{4}}-4 U^{2} v-\beta^{2}\right)}{16 U^{4} v^{2}+80 U^{2} v \beta^{2}+\beta^{4}}
\end{aligned}
$$

Proof of Proposition 4. Let

$$
\begin{aligned}
e_{d}^{t *}-e_{d}^{*}= & \frac{\sqrt{16 U^{4} v^{2}+80 U^{2} v \beta^{2}+\beta^{4}}-4 U^{2} v-\beta^{2}}{12 U v \beta} \\
& -\frac{\beta}{2 U v}=0 .
\end{aligned}
$$

Then there is

$$
\begin{aligned}
& e_{d}^{t *}-e_{d}^{*} \begin{cases}\leq 0, & \text { if } \frac{3}{4} \beta^{2} \leq U^{2} v \leq 2 \beta^{2} \\
>0, & \text { if } U^{2} v>2 \beta^{2},\end{cases} \\
& q_{d}^{t *}-q_{d}^{*} \\
& =\frac{8 U^{2} v-p \beta^{2}+\sqrt{16 U^{4} v^{2}+80 p U^{2} v \beta^{2}+p^{2} \beta^{4}}}{24 U v} \\
& -\frac{U}{2}-\frac{p \beta^{2}}{8 U v} \\
& =\frac{\sqrt{16 U^{4} v^{2}+80 U^{2} v \beta^{2}+\beta^{4}}-4 U^{2} v-4 \beta^{2}}{24 U v}>0 \\
& w_{d}^{t *}-w_{d}^{*} \geq 0 .
\end{aligned}
$$

Proof of Proposition 5. (1) Without capital constraints,

$$
\begin{aligned}
& \pi_{m}^{d *}=\frac{\left(4 U^{2} v+\beta^{2}\right)^{2}}{64 U^{3} v^{2}} \\
& \pi_{r}^{d *}=\frac{16 U^{4} v^{2}+8 U^{2} v \beta^{2}-15 \beta^{4}}{128 U^{3} v^{2}} \\
& \pi_{c}^{d *}=\frac{48 U^{4} v^{2}+24 U^{2} v \beta^{2}-13 \beta^{4}}{128 U^{3} v^{2}}
\end{aligned}
$$

(2) With capital constraints: let $K=$ $\sqrt{16 U^{4} v^{2}+80 U^{2} v \beta^{2}+\beta^{4}}$;

$$
\begin{aligned}
& \pi_{m}^{d t *}=\frac{1}{1728 U^{3} v^{2} \beta^{2}}\left(\beta^{4}\left(K-\beta^{2}\right)-64 U^{6} v^{3}\right. \\
& \left.\quad+40 U^{2} v \beta^{2}\left(2 K-3 \beta^{2}\right)+8 U^{4} v^{2}\left(21 \beta^{2}+2 K\right)\right) \\
& \pi_{r}^{d t *}=0 \\
& \pi_{c}^{d t *}=\frac{1}{1728 U^{3} v^{2} \beta^{2}}\left(\beta^{4}\left(K-\beta^{2}\right)-64 U^{6} v^{3}\right. \\
& \left.\quad+40 U^{2} v \beta^{2}\left(2 K-3 \beta^{2}\right)+8 U^{4} v^{2}\left(21 \beta^{2}+2 K\right)\right) \\
& \pi_{c}^{d t *}-\pi_{c}^{d *}=\frac{1}{3456 U^{3} v^{2} \beta^{2}}\left(349 \beta^{6}-128 U^{6} v^{3}\right. \\
& \quad+2 \beta^{4} K+32 U^{4} v^{2}\left(K-30 \beta^{2}\right) \\
& \left.\quad+8 U^{2} v \beta^{2}\left(20 K-111 \beta^{2}\right)\right) .
\end{aligned}
$$


It is easy to find that $\pi_{c}^{d t *}-\pi_{c}^{d *}$ is increasing in $K$, so let $\pi_{c}^{d t *}-\pi_{c}^{d *}=0$; there is

$$
K_{0}=\frac{128 U^{6} v^{3}+960 U^{4} v^{2} \beta^{2}+888 U^{2} v \beta^{4}-349 \beta^{6}}{2\left(16 U^{4} v^{2}+80 U^{2} v \beta^{2}+\beta^{4}\right)} .
$$

Recall that $K=\sqrt{16 U^{4} v^{2}+80 U^{2} v \beta^{2}+\beta^{4}}$; now we only need to compare $K_{0}$ and $K$.

$$
K^{2}-K_{0}^{2}=\frac{27 \beta^{4}\left(3072 U^{8} v^{4}+17152 U^{6} v^{3} \beta^{2}-1536 U^{4} v^{2} \beta^{4}+22992 U^{2} v \beta^{6}-4511 \beta^{8}\right)}{4\left(16 U^{4} v^{2}+80 U^{2} v \beta^{2}+\beta^{4}\right)^{2}} .
$$
that

To simplify writing, let $t=U^{2} v, t \geq 3 \beta^{2} / 4$; then it means

$$
\begin{aligned}
K> & K_{0} \\
& \mathbb{} \\
f(t)= & 3072 t^{4}+17152 t^{3} \beta^{2}-1536 t^{2} \beta^{4} \\
& \quad+22992 t \beta^{6}-4511 \beta^{8}>0, \quad t \geq \frac{3 \beta^{2}}{4} \\
& \Uparrow \quad \\
f^{\prime}(t)= & 48\left(256 t^{3}+1072 t^{2} \beta^{2}-64 t \beta^{4}+479 \beta^{6}\right) \\
> & 0, \quad t \geq \frac{3 \beta^{2}}{4} \\
& \mathbb{}
\end{aligned}
$$$$
f^{\prime \prime}(t)=1536\left(24 t^{2}+67 t \beta^{2}-2 \beta^{4}\right)>0, \quad t \geq \frac{3 \beta^{2}}{4}
$$$$
\Uparrow
$$$$
f^{\prime \prime \prime}(t)=1536\left(48 t+67 \beta^{2}\right)>0, \quad t \geq \frac{3 \beta^{2}}{4} .
$$

From the above analysis, $f(t)$ is increasing in $t$, when $t=$ $3 \beta^{2} / 4,\left.f(t)\right|_{t=3 \beta^{2} / 4}=20077 \beta^{8}>0$. Thus, $\pi_{c}^{d t *}-\pi_{c}^{d *}>0$.

\section{Conflicts of Interest}

The authors declare no conflicts of interest.

\section{Authors' Contributions}

Liming Zhao and Yao Song conceptualized and designed the study; Ling Li analysed the data and wrote the paper; Cong Li and Yujie Wu contributed the analysis tools. All authors read and approved the final manuscript.

\section{Acknowledgments}

This paper is supported by the National Planning Office of Philosophy and Social Science, China, no. 13\&ZD162.

\section{References}

[1] D. Yang and T. Xiao, "Pricing and green level decisions of a green supply chain with governmental interventions under fuzzy uncertainties," Journal of Cleaner Production, vol. 149, pp. 1174-1187, 2017.

[2] R. M. Vanalle, G. M. D. Ganga, M. Godinho Filho, and W. C. Lucato, "Green supply chain managementAn investigation of pressures, practices, and performance within the Brazilian automotive supply chain," Journal of Cleaner Production, vol. 151, pp. 250-259, 2017.

[3] S. Liu and Y.-T. Chang, "Manufacturers' closed-loop orientation for green supply chain management," Sustainability, vol. 9, no. 2, article 222, 2017.

[4] S. Vachon, "Green supply chain practices and the selection of environmental technologies," International Journal of Production Research, vol. 45, no. 18-19, pp. 4357-4379, 2007.

[5] R. B. Handfield, "Green supply chain: best practices from the furniture industry," in Proceedings of the Annual Meeting of the Decision Sciences Institute, vol. 3, pp. 1295-1297, Orlando, Fla, USA, November 1996.

[6] S. K. Srivastava, "Green supply-chain management: a state-ofthe-art literature review," International Journal of Management Reviews, vol. 9, no. 1, pp. 53-80, 2007.

[7] K. W. Green Jr., P. J. Zelbst, J. Meacham, and V. S. Bhadauria, "Green supply chain management practices: impact on performance," Supply Chain Management Review, vol. 17, no. 3, pp. 290-305, 2012.

[8] D. Pujari, "Eco-innovation and new product development: understanding the influences on market performance," Technovation, vol. 26, no. 1, pp. 76-85, 2006.

[9] X. Mu and L. Li, "Based on the differentiation strategy of environmental management and enterprise competitiveness study," Systems Engineering-Theory \& Practice, vol. 25, pp. 2631, 2005 (Chinese).

[10] A. Dumrongsiri, M. Fan, A. Jain, and K. Moinzadeh, "A supply chain model with direct and retail channels," European Journal of Operational Research, vol. 187, no. 3, pp. 691-718, 2008.

[11] U. Martinsen and M. Björklund, "Matches and gaps in the green logistics market," International Journal of Physical Distribution and Logistics Management, vol. 42, no. 6, pp. 562-583, 2012.

[12] P. Lin and Y. Huang, "The influence factors on choice behavior regarding green products based on the theory of consumption values," Journal of Cleaner Production, vol. 22, no. 1, pp. 11-18, 2012.

[13] G. Hartman, "Hartman report on sustainability: understanding the consumer perspective," Tech. Rep., Hartman Group, Bellevue, Wash, USA, 2007. 
[14] K. Govindan, S. G. Azevedo, H. Carvalho, and V. CruzMachado, "Impact of supply chain management practices on sustainability," Journal of Cleaner Production, vol. 85, pp. 212$225,2014$.

[15] P. Mahenc, "Are green products over-priced?" Environmental and Resource Economics, vol. 38, no. 4, pp. 461-473, 2007.

[16] M. A. Petersen and R. G. Rajan, "Trade credit: theories and evidence," Review of Financial Studies, vol. 10, no. 3, pp. 661691, 1997.

[17] M. Burkart and T. Ellingsen, "In-kind finance: a theory of trade credit," American Economic Review, vol. 94, no. 3, pp. 569-590, 2004.

[18] J. Murfin and K. Njoroge, "The implicit costs of trade credit borrowing by large firms," Review of Financial Studies , vol. 28, no. 1, pp. 112-145, 2015.

[19] X. Chen, "A model of trade credit in a capital-constrained distribution channel," International Journal of Production Economics, vol. 159, pp. 347-357, 2015.

[20] G. S. Amacher, E. Koskela, and M. Ollikainen, "Environmental quality competition and eco-labeling," Journal of Environmental Economics and Management, vol. 47, no. 2, pp. 284-306, 2004.

[21] Z. Liu and J. M. Cruz, "Supply chain networks with corporate financial risks and trade credits under economic uncertainty," International Journal of Production Economics, vol. 137, no. 1, pp. 55-67, 2012.

[22] L. Xia and L. He, "Game theoretic analysis of carbon emission reduction and sales promotion in dyadic supply chain in presence of consumers' low-carbon awareness," Discrete Dynamics in Nature and Society, vol. 2014, Article ID 837376, pp. 1-13, 2014.

[23] M. Abdullah, S. Zailani, M. Iranmanesh, and K. Jayaraman, "Barriers to green innovation initiatives among manufacturers: the Malaysian case," Review of Managerial Science, vol. 10, no. 4, pp. 683-709, 2016.

[24] Q. Zhang, J. Zhang, and W. Tang, "Coordinating a supply chain with green innovation in a dynamic setting," $4 O R$, vol. 15 , no. 2 , pp. 133-162, 2016.

[25] Z. Basiri and J. Heydari, "A mathematical model for green supply chain coordination with substitutable products," Journal of Cleaner Production, vol. 145, pp. 232-249, 2017.

[26] Y. Yu, X. Han, and G. Hu, "Optimal production for manufacturers considering consumer environmental awareness and green subsidies," International Journal of Production Economics, vol. 182, pp. 397-408, 2016.

[27] X. Xu, P. He, H. Xu, and Q. Zhang, "Supply chain coordination with green technology under cap-and-trade regulation," International Journal of Production Economics, vol. 183, pp. 433-442, 2017.

[28] G. Scur and M. E. Barbosa, "Green supply chain management practices: multiple case studies in the brazilian home appliance industry," Journal of Cleaner Production, vol. 141, pp. 1293-1302, 2017.

[29] G. Lai, L. G. Debo, and K. Sycara, "Sharing inventory risk in supply chain: the implication of financial constraint," Omega , vol. 37, no. 4, pp. 811-825, 2009.

[30] C. H. Lee and B.-D. Rhee, "Coordination contracts in the presence of positive inventory financing costs," International Journal of Production Economics, vol. 124, no. 2, pp. 331-339, 2010.

[31] C. H. Lee and B.-D. Rhee, "Trade credit for supply chain coordination," European Journal of Operational Research, vol. 214, no. 1, pp. 136-146, 2011.
[32] J. Luo and Q. Zhang, "Trade credit: a new mechanism to coordinate supply chain," Operations Research Letters, vol. 40, no. 5, pp. 378-384, 2012.

[33] B. Jing, X. Chen, and G. G. Cai, "Equilibrium financing in a distribution channel with capital constraint," Production Engineering Research and Development, vol. 21, no. 6, pp. 10901101, 2012.

[34] A. A. Taleizadeh, D. W. Pentico, M. Saeed Jabalameli, and M. Aryanezhad, "An EOQ model with partial delayed payment and partial backordering," Omega, vol. 41, no. 2, pp. 354-368, 2013.

[35] G. Cai, X. Chen, and Z. Xiao, "The roles of bank and trade credits: theoretical analysis and empirical evidence," Production Engineering Research and Development, vol. 23, no. 4, pp. 583598, 2014.

[36] B. Hou, J. Shi, and X. Zhuang, "A study on the external financing and coordination strategies of supply chain based on retailer's capital constraints," in Proceedings of the 28th Chinese Control and Decision Conference, CCDC 2016, pp. 4553-4558, Yinchuan, China, May 2016.

[37] J. Shi, J. Guo, and R. Y. K. Fung, "Decision support system for purchasing management of seasonal products: a capitalconstrained retailer perspective," Expert Systems with Applications, vol. 80, pp. 171-182, 2017.

[38] J. Shi, R. Y. Fung, and J. Guo, "Optimal ordering and pricing policies for seasonal products: impacts of demand uncertainty and capital constraint," Discrete Dynamics in Nature and Society, vol. 2016, Article ID 1801658, pp. 1-13, 2016.

[39] E. Falatoonitoosi, Z. Leman, and S. Sorooshian, "Modeling for green supply chain evaluation," Mathematical Problems in Engineering, vol. 2013, Article ID 201208, pp. 1-9, 2013.

[40] J. Cao and X. Zhang, "Coordination strategy of Green Supply Chain under the free market mechanism," Energy Procedia, vol. 36, pp. 1130-1137, 2013.

[41] S. Barari, G. Agarwal, W. J. Zhang, B. Mahanty, and M. K. Tiwari, "A decision framework for the analysis of green supply chain contracts: an evolutionary game approach," Expert Systems with Applications, vol. 39, no. 3, pp. 2965-2976, 2012.

[42] S. Swami and J. Shah, "Channel coordination in green supply chain management," Journal of the Operational Research Society, vol. 64 , no. 3, pp. 336-351, 2013.

[43] C.-T. Zhang and L.-P. Liu, "Research on coordination mechanism in three-level green supply chain under non-cooperative game," Applied Mathematical Modelling, vol. 37, no. 5, pp. 33693379, 2013.

[44] A. Xu and S. Gao, "A portfolio pricing model and contract design of the green supply chain for home appliances industry based on manufacturer collecting," in Proceedings of the 12th International Symposium on Distributed Computing and Applications to Business, Engineering and Science (DCABES '13), pp. 186-190, Kingston upon Thames, Surrey, UK, September 2013.

[45] C.-T. Zhang, H.-X. Wang, and M.-L. Ren, "Research on pricing and coordination strategy of green supply chain under hybrid production mode," Computers \& Industrial Engineering, vol. 72, no. 1, pp. 24-31, 2014.

[46] G. Xie, "Modeling decision processes of a green supply chain with regulation on energy saving level," Computers \& Operations Research, vol. 54, pp. 266-273, 2015.

[47] S. Hamdan and A. Cheaitou, "Dynamic green supplier selection and order allocation with quantity discounts and varying supplier availability," Computers \& Industrial Engineering, vol. 110, pp. 573-589, 2017. 
[48] D. Ghosh and J. Shah, "Supply chain analysis under green sensitive consumer demand and cost sharing contract," International Journal of Production Economics, vol. 164, pp. 319-329, 2015.

[49] L. Zhang, J. Wang, and J. You, "Consumer environmental awareness and channel coordination with two substitutable products," European Journal of Operational Research, vol. 241, no. 1, pp. 63-73, 2015.

[50] B. Li, M. Zhu, Y. Jiang, and Z. Li, "Pricing policies of a competitive dual-channel green supply chain," Journal of Cleaner Production, vol. 112, part 3, pp. 2029-2042, 2016.

[51] W. Zhu and Y. He, "Green product design in supply chains under competition," European Journal of Operational Research, vol. 258, no. 1, pp. 165-180, 2017.

[52] G. Y. Xu, B. Dan, X. M. Zhang, and C. Liu, "Coordinating a dual-channel supply chain with risk-averse under a two-way revenue sharing contract," International Journal of Production Economics, vol. 147, pp. 171-179, 2014. 


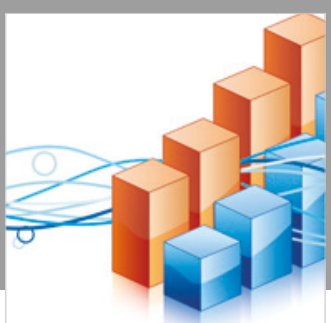

Advances in

Operations Research

\section{-n-m}
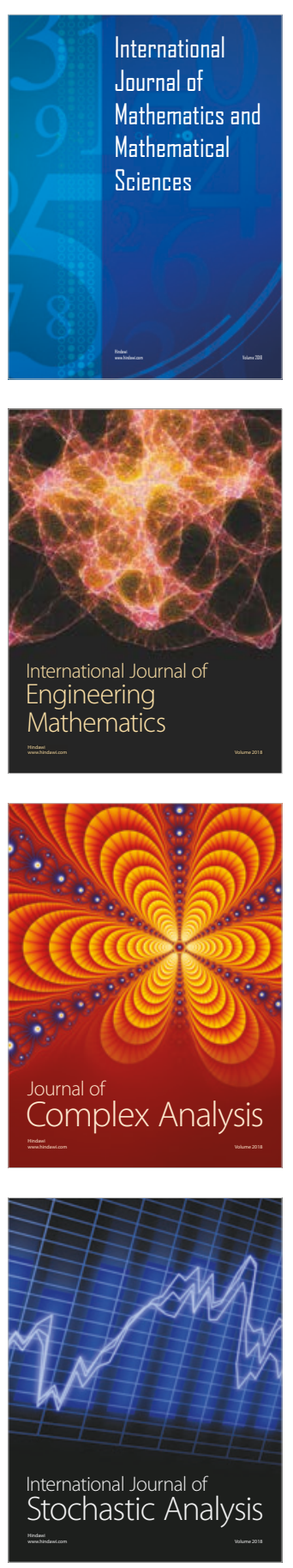
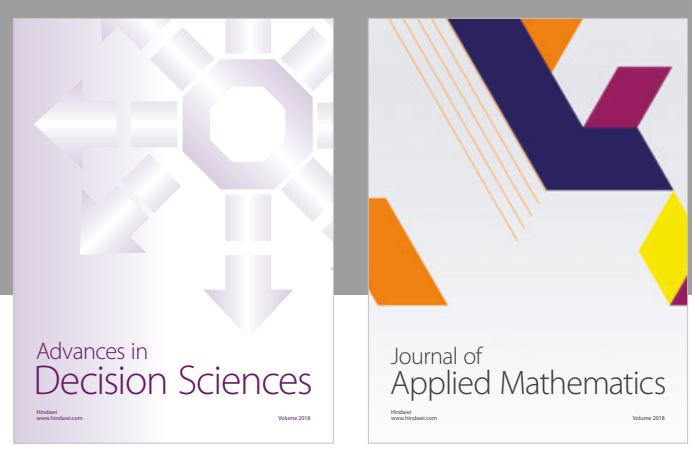

Journal of

Applied Mathematics
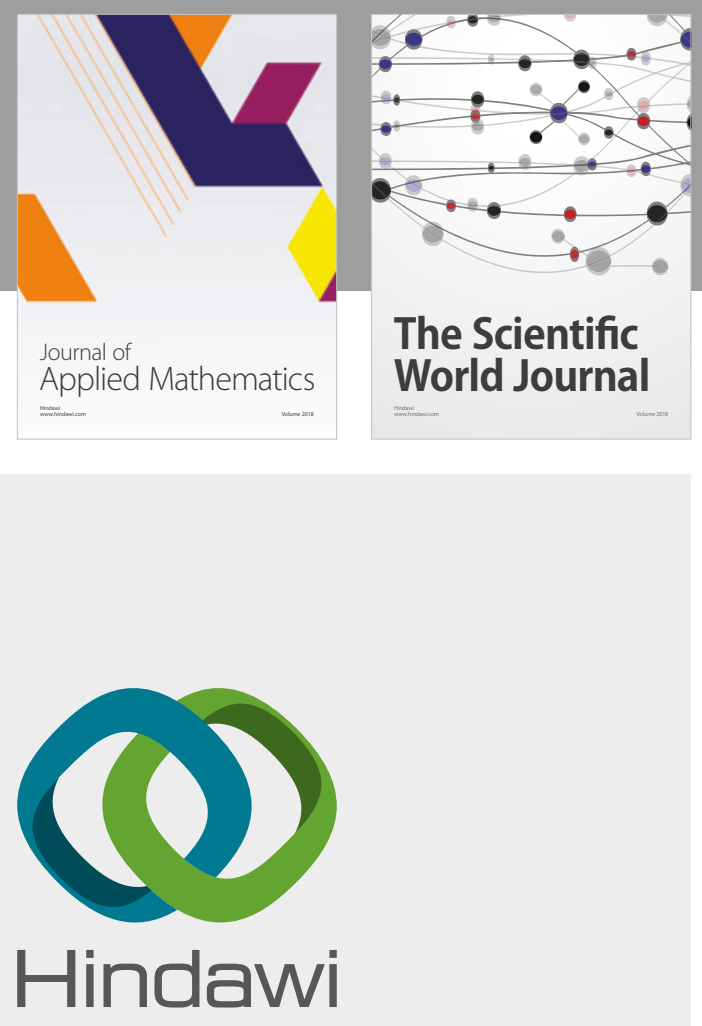

Submit your manuscripts at

www.hindawi.com

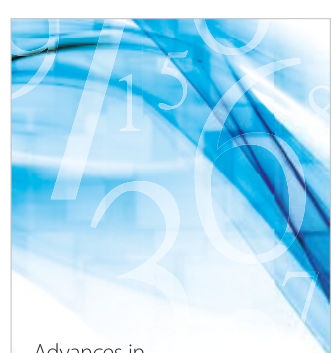

Advances in
Numerical Analysis
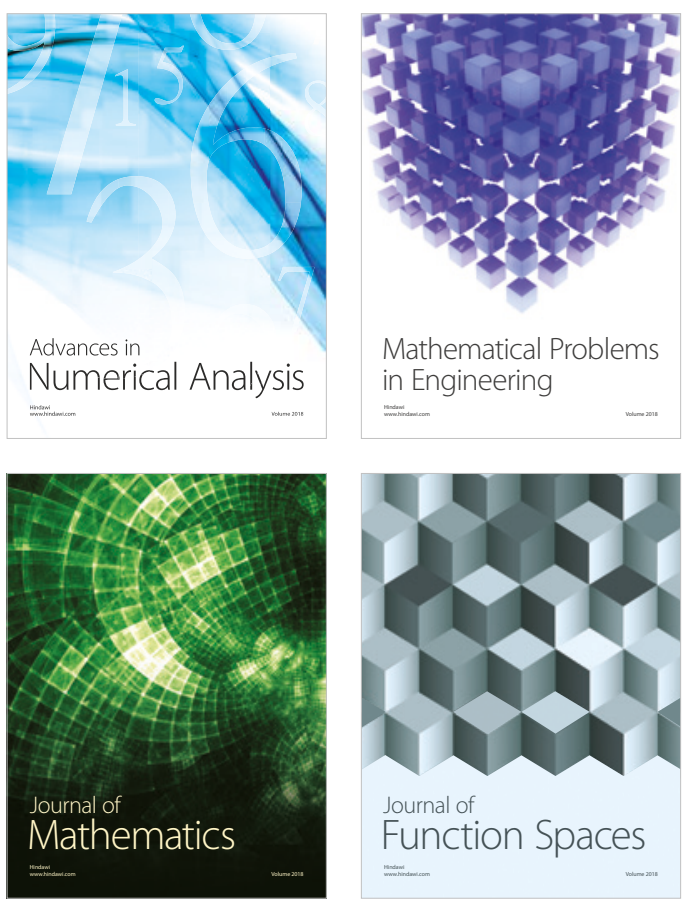

Mathematical Problems in Engineering

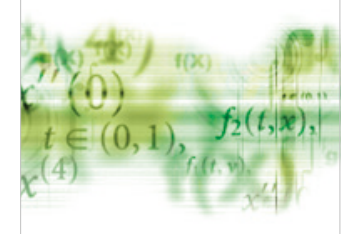

International Journal of

Differential Equations

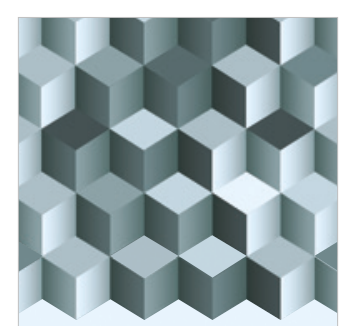

Journal of

Function Spaces
The Scientific

World Journal



Journal of

Probability and Statistics
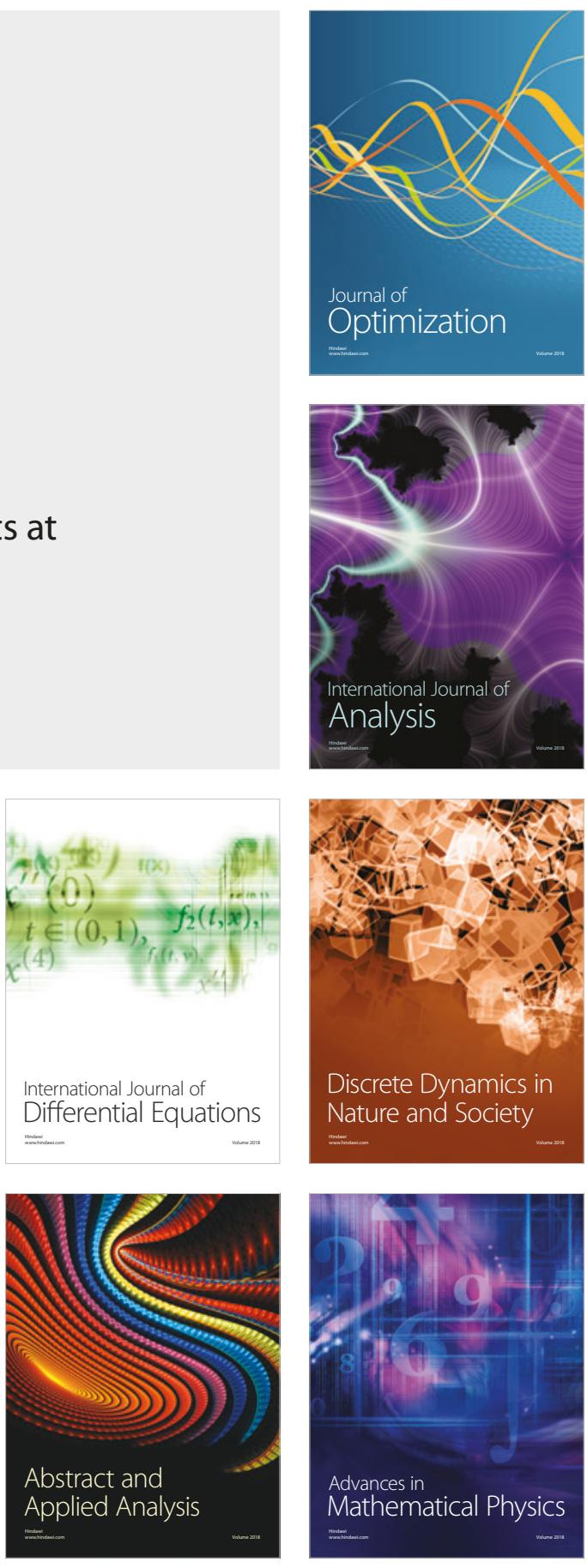